\title{
Avaliação da atividade antimicrobiana da planta Tradescantia pallida Munt (Taboquinha Roxa)
}

\author{
SILVA, A.M.A.P. ${ }^{* *}$; SILVA, A.M1; MASSON, R..; MOTA, R.D.'; COSTA, N.C.'; RIBEIRO, E.E.'; LOUREIRO, \\ W.A.S.'; FIGUEIREDO, P.M.S. \\ ${ }^{1}$ Centro Universitário do Maranhão - CEUMA, Departamento de Microbiologia, Rua Josué Montello, $n^{\circ} 1$, \\ Renascença, CEP: 65.075-120, São Luís, MA, Brasil. *Autor para correspondência: andressamirell@hotmail.com
}

\begin{abstract}
RESUMO: O objetivo deste estudo foi pesquisar o efeito antimicrobiano in vitro do extrato hidroalcóolico das folhas Tradescantia pallida Munt conhecida como Taboquinha roxa. Foram realizados testes em meio sólido, onde não observou qualquer halo de inibição, e o método de microdiluição, em que os resultados foram expressivos, com determinação da Concentração Inibitória Mínima (CIM) e Concentração Bactericida Mínima (CBM), com resultados em diferentes concentrações. Foram utilizadas cepas padrão de bactérias Gram positivas e Gram negativas. De acordo com os resultados, sugere-se que essa planta apresenta um potencial antimicrobiano.
\end{abstract}

Palavras-chave: Tradescantia pallida munt, Concentração Inibitória Mínima (CIM) e Concentração Bactericida Mínima (CBM).

\begin{abstract}
Evaluation of antimicrobial activity of the Tradescantia pallida Munt plant (Taboquinha Roxa). The aim of this study was to investigate the in vitro antimicrobial effect of the hydroalcoholic extract of the Tradescantia pallida Munt leaves, known as Taboquinha roxa. The tests were both conducted on solid mean, where it was not observed any zone of inhibition, and by the micro dilution method, in which the results of the Minimum Inhibitory Concentration (MIC) and the Minimum Bactericidal Concentration (MBC) were significant and related with the different concentrations. Standard strains of bacteria type Gram positive and Gram negative were employed. According to the results, this plant has an antimicrobial potential.
\end{abstract}

Keywords: Tradescantia pallida Munt, Minimum Inhibitory Concentration (MIC) and Minimum Bactericidal Concentration (MBC).

\section{INTRODUÇÃO}

A OMS define planta medicinal como sendo "todo e qualquer vegetal que possui, em um ou mais órgãos, substâncias que podem ser utilizadas com fins terapêuticos ou que sejam precursores de fármacos semissintéticos" (OMS, 1998).

Uma planta com característica medicinal possui substâncias ativas que provocam no organismo humano reações que podem variar da cura ao abrandamento da doença (Silva Júnior, 1994), e no Brasil, o uso das plantas com finalidade terapêutica vem crescendo exponencialmente (Nascimento et al. 2000). E o uso popular consolidado tem sido utilizado como guia para pesquisas farmacológicas que tem contribuído ao longo dos anos para obtenção de fármacos, atualmente utilizados na clínica (Yunes \& Cechinel Filho, 2001).

O uso milenar de plantas medicinais mostrou, ao longo dos anos, que determinadas plantas apresentam substâncias potencialmente perigosas. Do ponto de vista científico, pesquisas mostraram que muitas delas possuem substâncias potencialmente agressivas e, por esta razão, devem ser utilizadas com cuidado, respeitando seus riscos toxicológicos (Viega Júnior et al. 2005).

Assim também, vários estudos vêm demonstrando a ação terapêutica e entre as patologias tradicionalmente tratadas pelas plantas está às infecções, que tem sua atividade antimicrobiana comprovada através de testes que ofereçam confiabilidade científica (Fernandes Júnior et al. 2007).

A atividade antimicrobiana vai depender do teor de metabólitos secundários, do processamento e condições de estocagem e tipo do microrganismo em questão (Bertini et al., 2005). Alguns metabólitos apresentam ação contra bactérias Gram positivas e 
Gram negativas (Dorman \& Deans, 2000; Ushimaru et al., 2007) e ainda sobre leveduras e fungos filamentosos (Viegas et al., 2000).

A planta Tradescantia pallida Munt é conhecida por suas suntuosas folhas roxas, popularmente conhecida na região maranhense como taboquinha roxa. O gênero Tradescantia é muito utilizado em ornamentação por todo o país, sendo de fácil cultivo e propagação, possui alta resistência aos fatores climáticos e ambientais, assim como pode ser facilmente propagada vegetativamente (Savóia, 2007). Na região Nordeste, com indicação farmacológica age como um anódino, para reumatismos e dores nas articulações, onde suas folhas são usadas sob a forma de tintura (Oliveira, 2008). O objetivo deste estudo foi pesquisar o potencial antimicrobiano in vitro do extrato hidroalcóolico das folhas de Tradescantia pallida Munt.

\section{MATERIAL E MÉTODO Amostra vegetal}

As folhas da Tradescantia pallida Munt (Taboquinha roxa) foram adquiridas no herbário Terezinha Rego, Universidade Federal do Maranhão (UFMA), mês de junho de 2012 onde possui um exemplar da espécie sob o registro de $n^{\circ} 1272$.

\section{Bactérias}

Foram utilizadas cepas padrão de bactérias Gram-positivas (Staphylococcus aureus ATCC 25923, Staphylococcus aureus meticilina resistente MRSA ATCC 3438402, Staphylococcus aureus meticilina resistente MRSA ATCC 3436402, Streptococcus mutans ATCC 251919, Enterococcus faecalis ATCC 29212) e Gram-negativas (Escherichia coli ATCC 036157, Escherichia coli ATCC 25922, Proteus mirabilis ATCC 7003, Klebsiella pneumoniae ATCC L3889).

\section{Preparação do extrato}

O extrato bruto de Tradescantia pallida Munt foi obtido pela maceração de $48,9 \mathrm{~g}$ de folhas jovens da espécie, previamente trituradas e adicionadas a uma solução hidroalcóolica $70 \%$ (1:1) de $300 \mathrm{~mL}$ cada à temperatura ambiente com renovação de solvente a cada 24 horas durante três dias, e depois submetido a rotoevaporação (Janke e Kunkel@) para obtenção do volume concentrado que foi de 340 $\mathrm{ml}$, obteve-se o peso seco $0,0815 \mathrm{~g} / \mathrm{mL}$ e rendimento de $6,3 \%$ e em seguida foi colocado em frasco âmbar e conservado sob refrigeração(Das et al., 2010).

\section{Preparo das suspensões bacterianas}

As bactérias foram inicialmente reativadas a partir das suas culturas originais e mantidas em meio líquido $\mathrm{BHI}$ (Brain Heart Infusion) à $37^{\circ} \mathrm{C} / 24$ h. Posteriormente as amostras foram cultivadas em Ágar Muller Hinton a $37^{\circ} \mathrm{C} / 24 \mathrm{~h}$, as colônias isoladas foram então ressuspendidas em $5 \mathrm{~mL}$ de solução fisiológica ( $\mathrm{NaCl}$ 0,89\%) estéril até atingir turbidez equivalente na escala 0,5 de Mac Farland $\left(1,5 \times 10^{8}\right.$ bact $/ \mathrm{mL}$ ) (Figueira et al., 2004).

\section{Detecção da atividade antimicrobiana Método da Difusão em Meio Sólido}

O potencial antibacteriano do extrato hidroalcóolico foi avaliado pelo método de difusão em ágar por discos. As bactérias foram semeadas em meio sólido e testados em disco de papel filtro embebidos com $20 \mu \mathrm{L}(0,0815 \mathrm{~g} / \mathrm{mL})$ do extrato hidroalcóolico de Tradescantia pallida Munt, juntamente com discos de gentamicina $20 \mu \mathrm{g}$ como controle e incubados a $37^{\circ} \mathrm{C} / 24 \mathrm{~h}$. Após a incubação, foi medido o diâmetro de halo de inibição de crescimento quando presente (Santos et al., 2007).

\section{Método de Microdiluição}

Foram preparadas diluições seriadas do extrato Tradescantia pallida Munt com caldo BHI, e a seguir adicionados $100 \mu \mathrm{L}$ suspenções bacterianas. Em outro tubo preparou-se outra diluição de caldo $\mathrm{BHI}$ com antimicrobiano cloranfenicol $0,1 \%$ e $100 \mu \mathrm{L}$ de suspensões bacterianas, para controle negativo. Levou-se à estufa bacteriológica onde foi mantido por $24 \mathrm{~h}$. Após a incubação, observou- se a ocorrência da inibição do crescimento, medido em absorbância no comprimento de onda 490nm (Koneman, 2008).

\section{Determinação da Concentração Inibitória Mínima (CIM)}

Inicialmente $3 \mathrm{~mL}$ de caldo $\mathrm{BHI}$ foram transferidos em tubos de vidros estéreis. Posteriormente foram pipetado $3 \mathrm{~mL}$ de diluições seriadas estéreis do extrato hidroalcóolico de Tradescantia pallida Munt $(1 / 2,1 / 4,1 / 8,1 / 16)$. Em cada tubo foi adicionado $100 \mu \mathrm{L}$ de cada suspenção bacteriana. Os tubos foram em seguida homogeneizados com auxílio do vórtex em baixa velocidade e incubados a $37^{\circ} \mathrm{C} / 24 \mathrm{~h}$ em estufa bacteriológica. A CIM foi à menor concentração do extrato hidroalcóolico de Tradescantia pallida Munt onde não houve crescimento bacteriano visível, também medido em absorbância no comprimento de onda 490nm (Chaud et al., 2005).

\section{Determinação da Concentração Bactericida Mínima (CBM)}

Os tubos incubados para determinação da CIM em meio líquido foram utilizados para a determinação da Concentração Bactericida Mínima (CBM). Uma alíquota de cada tubo foi inoculada 
em placas $\mathrm{BHI}$ Agar e posteriormente incubada em estufa bacteriológica a $37^{\circ} \mathrm{C} / 24 \mathrm{~h}$. A CBM é a menor concentração do extrato onde não houver crescimento bacteriano, ou seja, onde houve $99,9 \%$ de morte bacteriana (Duarte et al., 2003).

\section{RESULTADOS E DISCUSSÃO}

O resultado da atividade antimicrobiana "in vitro" do extrato hidroalcoólico da planta Tradescantia pallida Munt pelo Método da Microdiluição, mostra as diluições realizadas até obter a Concentração Inibitória Mínima (CIM). Observou que dentre as bactérias analisadas extrato apresentou atividade inibitória nas diluições $1 / 4,1 / 8$, tendo como controle positivo, cloranfenicol 0,1\%, conforme Tabela 1 .

De acordo com a Tabela1, verificou-se atividade inibitória em menores concentrações contra as bactérias, Klebsiella pneumoniae ATCC L3889, Staphylococcus aureus ATCC 25923, Staphylococcus aureus meticilina resistente MRSA ATCC 3438402 e Staphylococcus aureus meticilina resistente MRSA ATCC 3436402 e Enterococcus faecalis ATCC 29212.

Estudos indicam que bactérias pertencentes ao gênero Staphylococcus são responsáveis por infecções como furúnculo, conjuntivites, indivíduos debilitados por doenças crônicas, pneumonias, endocardites, meningites. E, algumas cepas que infectam pacientes hospitalizados, que são resistentes à maioria dos antibióticos disponíveis, como $S$. aureus resistentes à meticilina/oxacilina (MRSA), (Silva, 1999).

Os Enterococos são habitantes da microbiota do trato digestivo humano e de outros animais, apresentando baixa patogenicidade. No entanto, são causa de infecções urinárias e intraabdominais, endocardite e sepse, comportando-se, muitas vezes, como um agente oportunista em infecções nosocomiais. Os enterococos podem ser causa de pelo menos $10 \%$ das infecções hospitalares e em algumas casuísticas situa-se em terceiro lugar como causa destas infecções, após Escherichia coli e Staphylococcus aureus (Tavares, 2000).

Já Klebsiella pneumoniae é uma bactéria Gram negativa patogênica em causar pneumonias caracterizada por causar emissão de escarro sanguinolento e infecções do trato urinário, principalmente em pacientes cateterizados, (Silva, 1999).

Esta variação em relação à presença de atividade antimicrobiana pode estar relacionada não só a características da planta, uma vez que diferentes espécies apresentam diferentes princípios ativos, como também com as características das cepas testadas e da metodologia empregada. Por exemplo, alguns autores utilizam o método de difusão em disco para analisar a atividade antimicrobiana (Viegas et al., 2000; Bertini et al., 2005) enquanto outros utilizam a diluição (Sforcin et al., 2000; Ushimaru et al., 2007) apresentando resultados mais expressivos, o que ratifica os resultados do nosso trabalho, pois, a inibição do extrato frente às bactérias testadas ocorreu no método da microdiluição e não em meio sólido, já que não observou nenhum halo de inibição.

A Tabela 2 demonstra os resultados da determinação da Concentração Bactericida Mínima (CIM), onde as concentrações do extrato hidroalcóolico apresentaram ação bactericida, na diluição 1/2, com exceção das cepas Klebsiella pneumoniae ATCC L3889 e Enterococcus faecalis 29212, onde a concentração inibitória mínima foi $0,010 \mathrm{~g} / \mathrm{mL}$, na diluição $1 / 8$. No entanto, apresentou efeito bacteriostático frente à bactéria Staphylococcus aureus meticilina resistente (MRSA) ATCC 3436402, pois houve crescimento em todos os tubos inoculados.

De acordo com os resultados, observa-

TABELA 1. Determinação da Concentração Inibitória Mínima (CIM) in vitro do extrato hidroalcóolico da Tradescantia pallida Munt.

\begin{tabular}{lccc}
\hline Bactéria & $\begin{array}{c}\text { Concentração do } \\
\text { extrato }(\mathbf{g} / \mathbf{m l})^{\mathbf{a}}\end{array}$ & $\begin{array}{c}\text { Titulo } \\
\mathbf{( C N}^{\mathbf{c}}\end{array}$ \\
\hline Staphylococcus aureus ATCC 25923, & $0,010^{\mathrm{b}}$ & $1 / 8$ & 0 \\
Staphylococcus aureus meticilina resistente MRSA ATCC 3438402 & 0,010 & $1 / 8$ & 0 \\
Staphylococcus aureus meticilina resistente MRSA ATCC 3436402 & 0,010 & $1 / 8$ & 0 \\
Streptococcus mutans ATCC 251919 & 0,020 & $1 / 4$ & 0 \\
Enterococcus faecalis ATCC 29212 & 0,010 & $1 / 8$ & 0 \\
Escherichia coli ATCC 036157 & 0,020 & $1 / 4$ & 0 \\
Proteus mirabilis ATCC 7003 & 0,020 & $1 / 4$ & 0 \\
Klebsiella pneumoniae ATCC L3889 & 0,010 & $1 / 8$ & 0 \\
Escherichia coli ATCC 25922 & 0,020 & $1 / 4$ & 0 \\
\hline
\end{tabular}

a Extrato hidroalcóolico das folhas Tradescantia pallida Munt $(0,0815 \mathrm{~g} / \mathrm{mL})$, ${ }^{\mathrm{b}}$ Concentração Inibitória Mínima (CIM) para inibição do crescimento bacteriano em $\mathrm{g} / \mathrm{mL},{ }^{\circ} \mathrm{CN}=$ Controle Negativo - etanol $70 \%$. 
TABELA 2. Determinação da Concentração Bactericida Mínima (CBM) in vitro do extrato hidroalcóolico da Tradescantia pallida Munt em bactérias, cepas ATCC.

\begin{tabular}{lcc}
\hline Bactéria & $\begin{array}{c}\text { Concentração do } \\
\text { extrato } \mathbf{( g / m l} \mathbf{m}^{\mathbf{a}}\end{array}$ & Titulo \\
\hline Staphylococcus aureus ATCC 25923 & $0,041^{\mathrm{b}}$ & $1 / 2$ \\
Staphylococcus aureus meticilina resistente MRSA ATCC 3438402 & 0,041 & $1 / 2$ \\
Staphylococcus aureus meticilina resistente MRSA ATCC 3436402 & 0,0 & Não ocorreu inibição \\
Streptococcus mutans ATCC 251919 & 0,020 & $1 / 4$ \\
Enterococcus faecalis ATCC 29212 & 0,010 & $1 / 8$ \\
Escherichia coli ATCC 036157 & 0,041 & $1 / 2$ \\
Proteus mirabilis ATCC 7003 & 0,041 & $1 / 2$ \\
Klebisiella pneumoniae ATCC L3889 & 0,010 & $1 / 8$ \\
Escherichia coli ATCC 25922 & 0,041 & $1 / 2$ \\
\hline
\end{tabular}

aExtrato hidroalcóolico das folhas Tradescantia pallida $(0,0815 \mathrm{~g} / \mathrm{mL}),{ }^{,}$Concentração mínima para inibição do crescimento microbiano em $\mathrm{g} / \mathrm{mL}$.

se uma variabilidade quanto o efeito bactericida tanto em cepas Gram positivas quanto em Gram negativas. É provável que esta diferença de atividade antimicrobiana esteja relacionada não só a atividade biológica do extrato vegetal, mas também devido à presença de uma das estruturas da membrana externa das bactérias Gram negativas, que pode impedir a passagem de moléculas através desta membrana (França et al., 2009), além de particularidades relacionadas aos diferentes mecanismos de resistência das linhagens em estudo. No entanto, são necessários mais estudos para Tradescantia pallida Munt, a fim de caracterizar físico-química, farmacológica e toxicológica, visando o uso racional e aplicações futuras como antimicrobiano.

\section{REFERÊNCIA}

BERTINI, L.M. et al. Perfil de sensibilidade de bactérias frente a óleos essenciais de algumas plantas do nordeste do Brasil. Revista Infarma, v.17, n.314, p.803, 2005.

CHAUD, M.U. et al. Avaliação da atividade antimicrobiana de extratos vegetais. Revista Brasileira de Farmacognosia. v.15, p.316-20, 2005.

DAS, K. et al. Techniques for evaluation of medicinal plant products as antimicrobials agent: Current methods and future trends. Journal of Medicinal Plants Research. v.4(2), p. 104-11, 2010.

DORMAN, H.J.D.; DEANS, S.G. Antimicrobial agents from plants: antibacterial activity of plant volatile oils. Journal of Applied Microbiology. v.88, n.2, p.308-16, 2000.

DUARTE, S. et al. Effect of a novel type of propolis and its chemical fractions on glucosyltransferases and on growth and adherence of mutans streptococci. Biological \& Pharmaceutical Bulletin. v.26, n.4, p. 527-31, 2003

FERNANDES JUNIOR, A. et al. Antibacterial activity of medicinal plant extracts. Brazilian Journal of
Microbiology. v. 38, p. 717-19, 2007.

FIGUEIRA, G.M. et al. Atividade antimicrobiana de extratos hidroalcóolicos de espécies da coleção de plantas medicinais CPQBA/UNICAMP. Revista Brasileira de Farmacognosia, v.14, p.6-8, 2004.

FRANÇA, H.S. et al. Atividade antibacteriana de floroglucinóis e de extrato hexânico de Hypericum brasiliense Choysi. Química Nova, v.32, p.1103-6, 2009.

KONEMAN, E.W. Diagnóstico Microbiológico texto e atlas colorido. 6. ed. Rio de Janeiro: Guanabara Koogan, 2008, 1760p.

NASCIMENTO, G. F. et al. Antibacterial activity of plant extracts and phytochemicals on antibiotic resistant bacteria. Brazilian Journal of Microbiology. v.31, n.4, p.247-56, 2000.

OLIVEIRA, J.M. Núcleo de Estudos e Pesquisa em Fitoterapia, $\mathrm{dr}^{\mathrm{a}}$ Terezinha Rego. Memento Fitoterápico. Delta: São Luís, 2008, p.27.

ORGANIZAÇÃO MUNDIAL DA SAÚDE(OMS). Quality control methods for medicinal plants methods. p. 41 $-3,1998$.

SANTOS, S.C. et al. Atividade antimicrobiana in vitro do extrato de Albarema cochliocarpos (Gomes) Barneby \& Grimes. Revista Brasileira de Farmacognosia. v.17, p. 215-19, 2007.

SAVÓIA, E.J.L. Potencial de Tradescantia pallida cv. Purpurea para biomonitoramento da poluição aérea de Santo André - São Paulo, por meio do bioensaio Trad - MCN e do acúmulo foliar de elementos tóxicos. 2007. 102 p. Dissertação (Mestrado em Fisiopatologia Experimental) - Faculdade de Medicina da Universidade de São Paulo, USP, São Paulo.

SFORCIN, J.M. et al. Seasonal effect on Brazilian propolis antibacterial activity. Journal of Ethnopharmacology. v.73, p.243-9, 2000.

SILVA JUNIOR, A. A. et al. Plantas medicinais, caracterização e cultivo. Florianópolis: EPAGRI, 1994, p.71.

SILVA, C.H.P.M. Bacteriologia: um texto ilustrado. Rio de Janeiro: Eventos, 1999, p.531.

USHIMARU, P.I. et al. Antibacterial activity of medicinal plants. Brazilian
Journal of Microbiology. v.38, 
n.4, p.717- 9, 2007.

VIEGAS, E.C. et al. Toxicidade de óleos essenciais de alho e casca de canela contra fungos do grupo Aspergillus flavus. Revista Horticultura Brasileira, v.23, n.4, p.915-19, 2000.

VEIGA JUNIOR, V.F.V. et al. Plantas medicinais: cura segura? Química Nova, v.28, p.519-28, 2005.

TAVARES, W. Bactérias gram-positivas problemas: resistência do estafilococo, do enterococo e do pneumococo aos antimicrobianos. Revista da Sociedade Brasileira de Medicina Tropical. v.33, p.281-301, 2000.

YUNES, R.A.; CECHINEL FILHO, V.; Fármacos e fitoterápicos: a necessidade do desenvolvimento de indústria de fitoterápicos no Brasil. Química Nova. v.24, p.147-52, 2001. 